Article

\title{
Invertebrate Responses to Restoration across Benthic and Hyporheic Stream Compartments
}

\author{
Anne L. Robertson ${ }^{1, *(\mathbb{D}}$, Daniel M. Perkins ${ }^{1}$, Judy England ${ }^{2} \mathbb{D}$ and Tim Johns ${ }^{2}$ \\ 1 Department of Life Sciences, University of Roehampton, Holybourne Avenue, London SW15 4JD, UK; \\ Daniel.perkins@roehampton.ac.uk \\ 2 Environment Agency, Horizon House, Deanery Rd, Bristol BS1 5AH, UK; \\ judy.england@environment-agency.gov.uk (J.E.); tim.johns@environment-agency.gov.uk (T.J.) \\ * Correspondence: a.robertson@roehampton.ac.uk
}

Citation: Robertson, A.L.; Perkins, D.M.; England, J.; Johns, T.

Invertebrate Responses to Restoration across Benthic and Hyporheic Stream Compartments. Water 2021, 13, 996. https://doi.org/10.3390/w13070996

Academic Editor: Thomas Hein

Received: 5 March 2021

Accepted: 2 April 2021

Published: 4 April 2021

Publisher's Note: MDPI stays neutral with regard to jurisdictional claims in published maps and institutional affiliations.

Copyright: (c) 2021 by the authors. Licensee MDPI, Basel, Switzerland. This article is an open access article distributed under the terms and conditions of the Creative Commons Attribution (CC BY) license (https:// creativecommons.org/licenses/by/ $4.0 /)$.

\begin{abstract}
River restoration is a multi-billion-dollar business, yet it is unclear whether benthic community health, which is routinely monitored, can be used as a proxy for the health of the hyporheos. Applying a Before-After-Control-Impact approach to a UK case study, we compared the effects of removing an impoundment on the hyporheos with effects on the benthos. We compared invertebrate biological traits that we expected to respond to the restoration. We constructed sample-size based diversity curves and determined $\beta$-diversity between compartments and reaches. Two years postrestoration, hyporheic taxon richness was significantly lower in the restored reach compared to the control. However, three years post-restoration taxon richness was significantly higher in the impact reach. The composition of the control and impact reach hyporheos was most dissimilar at the first sampling time point post-restoration and at this time there was a universal decrease in the relative abundance of burrowing organisms respiring through gills. We did not detect a signal of restoration on benthic assemblage diversity and composition, perhaps because reach-scale restorations can be overwhelmed by catchment-scale disturbances. Thus, the hyporheos and the benthos responded differently to restoration. Given the importance of the hyporheic zone in the provision of ecosystem function and services, it is clear that it should be included in future monitoring protocols that aim to assess river restoration success.
\end{abstract}

Keywords: riverine connectivity; groundwater-fed rivers; diversity estimates; dissimilarity index; BACI; biological traits

\section{Introduction}

Rectifying historic alterations to river systems is now a multi-billion-dollar industry [1]. In the past, restoration activities have focused on improving channel morphology with the expectation that biodiversity recovery will follow [2]. However, biodiversity improvements are often slow or non-existent [3], leading to a move to 'functional' river restorations [4] that aim to restore the biogeochemical, ecological, and hydrogeomorphic processes in rivers. However, research on assessing the efficacy of such functional restoration projects is in its infancy [5].

It is widely accepted that rivers comprise three dimensions: longitudinal, lateral and vertical, and that connectivity between these compartments is vital for the delivery of the ecosystem functions and services that rivers provide [6]. The vertical element of this continuum is termed the hyporheic zone; an ecotone where surface water and groundwater interact and is known to play a major role in river functioning, acting as a bioreactor by recycling carbon, energy, and nutrients $[7,8]$ and attenuating pollutants, e.g., $[9,10]$. The composition, abundance and biomass of the hyporheic zone community (hyporheos), and thus its ability to mediate biogeochemical activity, are strongly influenced by the physical and chemical conditions within the hyporheic zone [11]. Sediment grain size, and by extension interstitial pore size, are important variables as they determine the living space 
available to the hyporheos and are strongly related to the porosity and permeability of the sediment [12]. In turn, this influences the hyporheic exchange flow [13,14], determining the supply of organic matter and dissolved oxygen in the hyporheic zone and therefore the distribution and abundance of the hyporheos [11].

Even though the hyporheos mediates biogeochemical processes, very few river restoration studies on the hyporheic zone have considered the biological community but see [15]. Existing research suggests that some common river restoration techniques incidentally benefit the hyporheos because they improve surface and hyporheic zone connectivity. Examples include flushing fine sediment from benthic gravels to improve fish spawning areas, e.g., [16], and removing weirs to increase exchange processes and decrease residence times [17]. Furthermore, no previous studies have examined simultaneous responses of the benthic and hyporheic communities in the context of river restoration. Indeed, it is very rare for studies to adopt a coupled benthic-hyporheic zone sampling strategy to address any research question but see [18-26]. These studies yielded mixed results; James et al. detected no differences in the response of benthic and hyporheic communities to drought [20], whereas Stubbington et al. did [23]. It therefore remains unclear whether benthic community health, which is routinely monitored, provides a proxy for the health of the hyporheos or whether both communities should be routinely monitored.

In this study, we assess the effects of removing an impoundment, by notching a weir, on the hyporheos and compare it to that on the benthos. We do this by comparing these two communities in a control (no restoration) and an impact (restoration) reach of the River Lambourn, in southern England, UK. We collected benthic and hyporheic samples in both reaches in two seasons (spring and autumn) 1 year before restoration and at 2, 3 and 5 years post restoration, to track community change.

We hypothesise that:

1. The hyporheos in the impact reach will differ more strongly in diversity and composition pre- and post-restoration than the control reach, since we expect weir notching will result in an increase in exchange processes between the surface stream and hyporheic zone.

2. The responses of the hyporheos to the restoration will differ from the benthos because they are discrete communities [27] driven by differing environmental variables.

\section{Methods}

\subsection{Restoration Scheme}

The purpose of the restoration was to restore natural river processes by improving hydraulic and sediment connectivity. The restoration took place on a stretch of the upper River Lambourn (Figure 1) in the autumn of 2013. Works involved the notching of an $8 \mathrm{~m}$ wide weir, which was impounding approximately $150 \mathrm{~m}$ of river and the narrowing of the channel using reworked gravels and brushwood. A more natural sinuous channel with exposed and vegetated gravel bars was created.

To assess the effects of the restoration, invertebrate monitoring of the benthic and hyporheic zone was carried out at two sites (control and impact site; see Figures 2 and 3). The control site was located upstream of the previous impounding influence of the weir and without any tributaries or discharges entering the channel between the two sites. Physical characteristics of the two sites during the study period are given in Supplementary Materials, Table S1. 


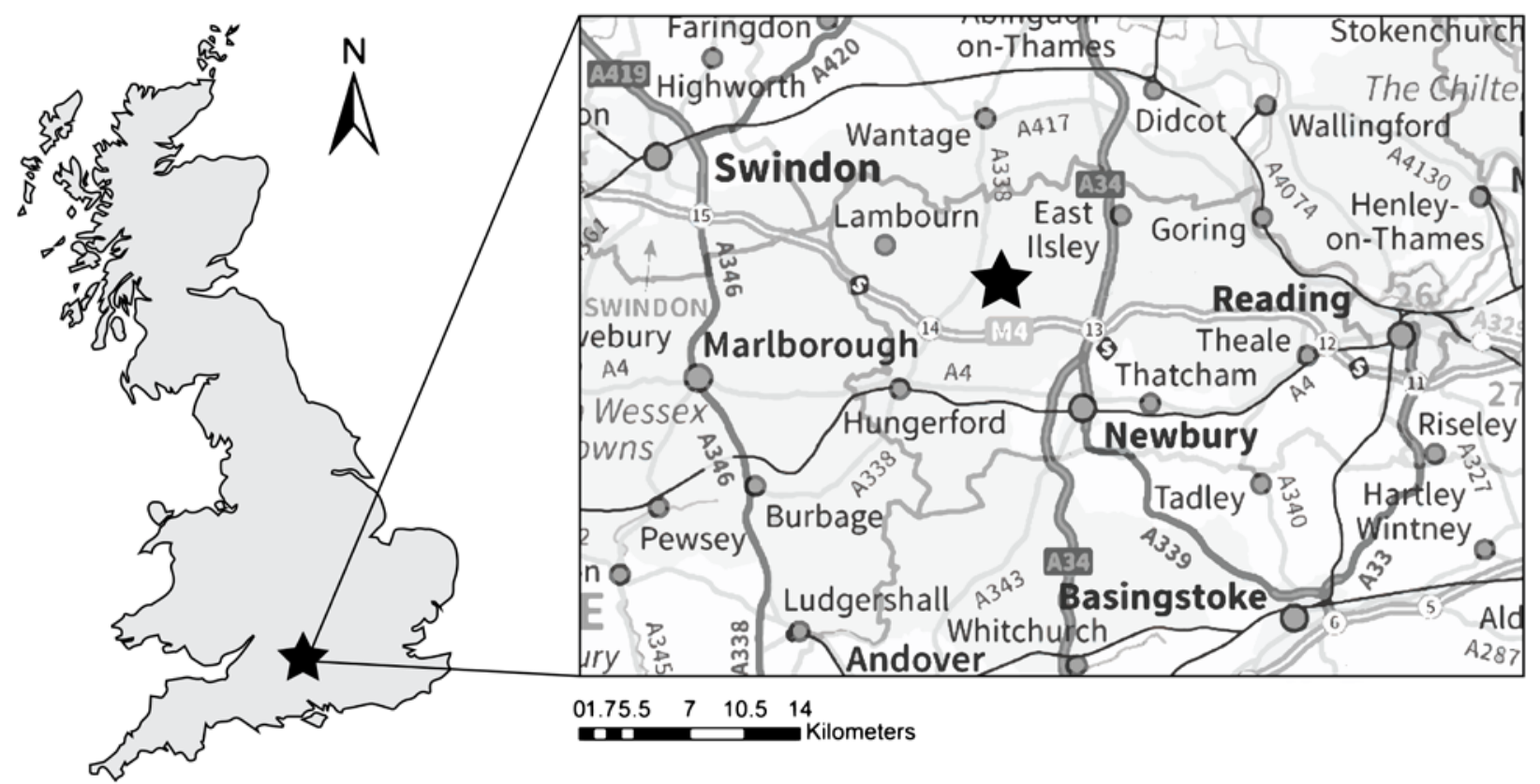

Figure 1. Study site location on the River Lambourn, southern England, UK. (C Environment Agency 2021. All rights reserved. (C) Crown copyright and database rights 2021 Ordnance Survey 100024198.

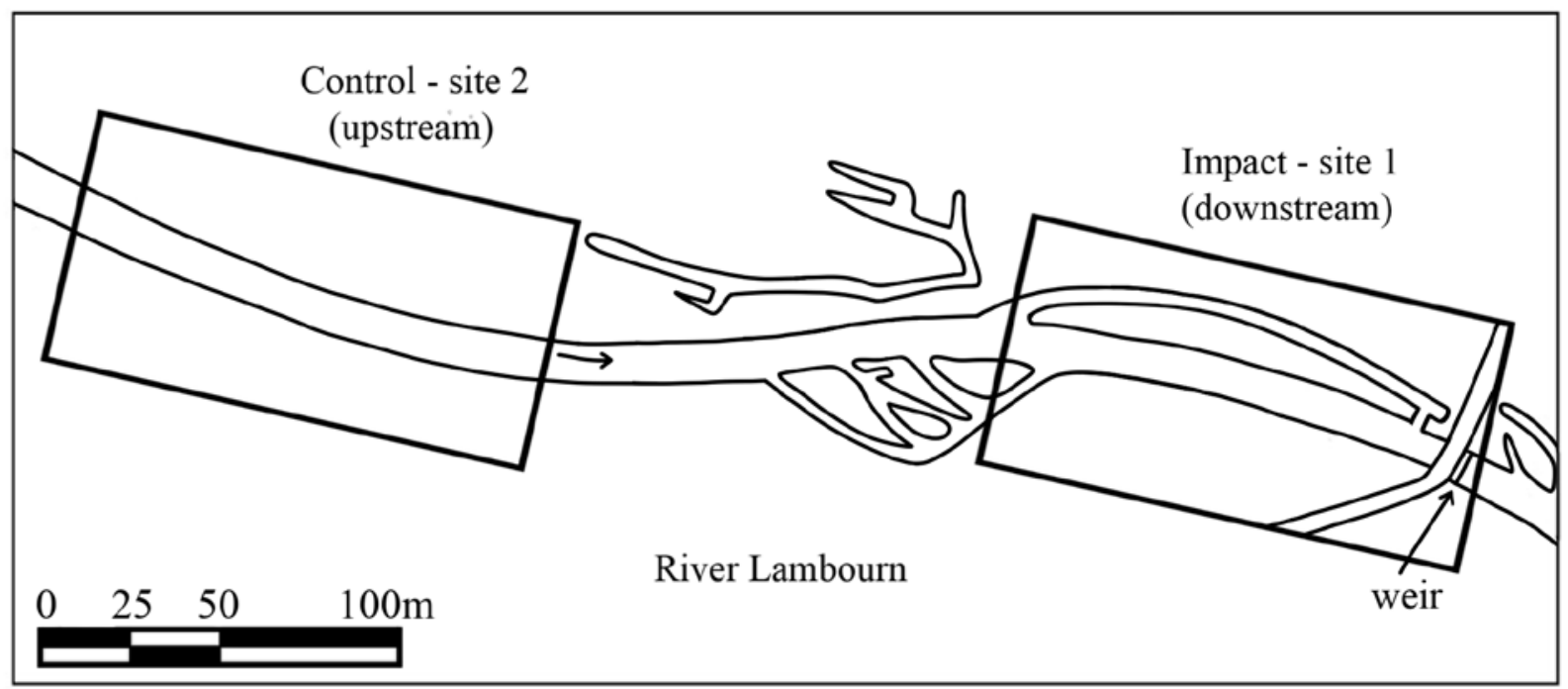

Figure 2. Location of Control (site 2) and Impact (site 1) sites on the River Lambourn. Arrow represents direction of water flow. 
Upstream (site 2)
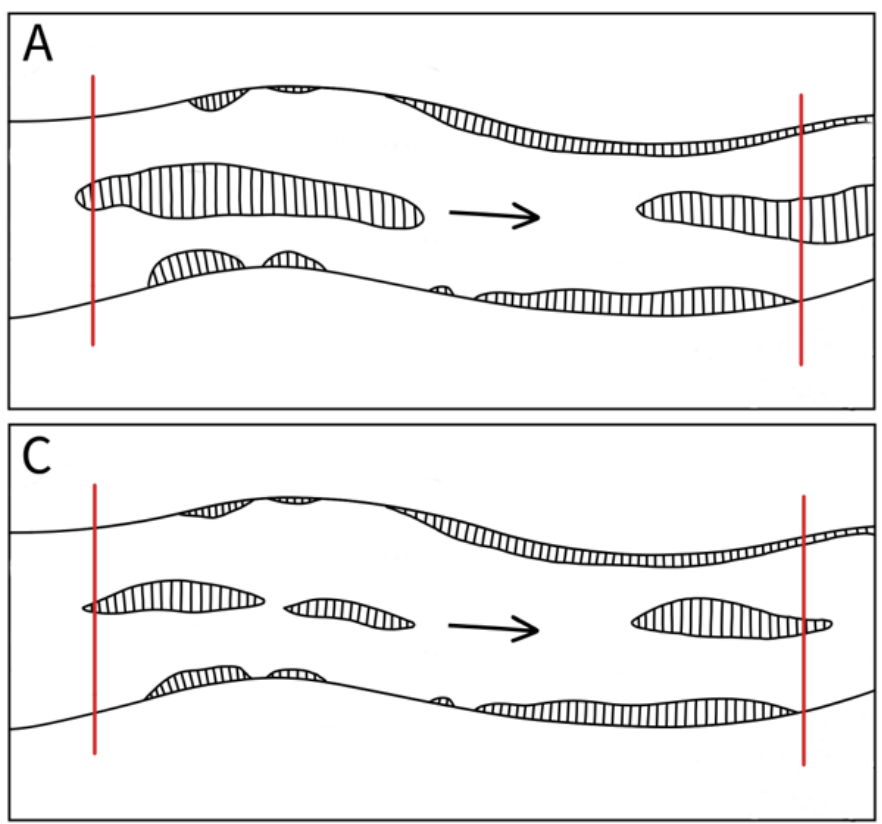

Downstream (site 1)
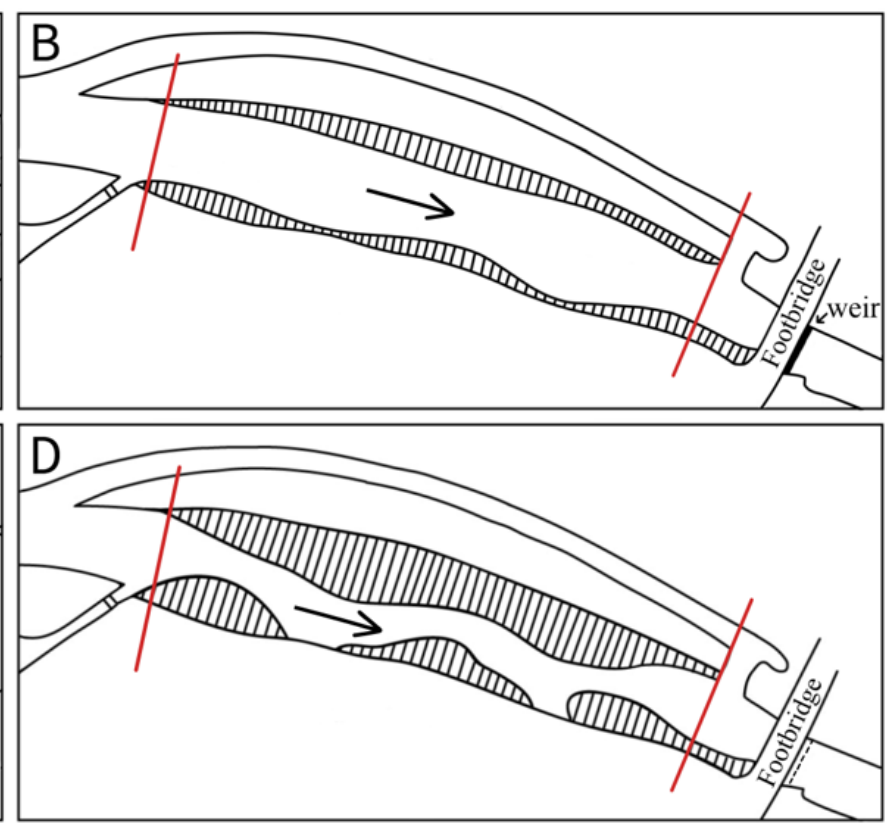

\section{$\begin{array}{llll}0 & 5 & 10 & 20 \mathrm{~m}\end{array}$}

Figure 3. Control (site 2) and Impact (site 1) before (A,B, 2013) and after restoration (C,D, 2018). Red lines indicate extent of surveyed stretch. Hatching indicates bank and instream features (e.g., plant growth and gravel bars). Arrows represent direction of water flow.

\subsection{Sampling}

To assess the invertebrate communities of the hyporheos and benthos prior to restoration, sampling took place at both control and impact sites in spring and autumn 2013. Restoration works began shortly after autumn monitoring, but due to extensive flooding in the area, no samples were taken in 2014. Post restoration monitoring took place in spring and autumn 2, 3 and 5 years post restoration (2015, 2016 and 2018 respectively).

The invertebrate community inhabiting the hyporheic zone was sampled using a Bou Rouch pump [28]. With the pump shaft inserted to $30 \mathrm{~cm}$ below river bed level, five litres of river water after $[29,30]$ were extracted at five locations at each site (five replicates per sampling occasion). A $30 \mathrm{~cm}$ depth was selected because previous studies on the Lambourn [31] and on other chalk streams have shown that the hyporheic zone is very shallow compared to rivers draining other geologies, e.g., [32,33]. The locations of sampling points were approximately ten meters apart, zig-zagging across the river. Extracted water samples were poured from the collection bucket through a $63 \mu \mathrm{m}$ plankton net, and the contents were bagged and preserved in industrial methylated spirit (IMS). A total of 80 samples were collected. In the laboratory, invertebrates were separated from sediment, and identified to species where possible using a dissecting microscope at 40-400× magnification.

The invertebrate community inhabiting the benthic zone was sampled using a standardised kick sample method [34]; the bed of the river is disturbed by kicking the substrate whilst zig-zagging in an upstream direction. A pond net $(150 \mathrm{~mm}$ frame with a $250 \mu \mathrm{m}$ mesh), trailed behind the kicking leg, catches dislodged fauna. The 3-min of sampling are proportionate to the extent of the microhabitats present. A further 1-min hand search is undertaken, and any additional fauna added to the net. The samples collected by this method were transferred to a container and preserved in IMS. In the laboratory, the samples 
were processed and invertebrates identified to species where taxonomically possible using a dissecting microscope at 40-400× magnification.

\subsection{Analysis}

Both hyporheic and benthic invertebrate data sets were pooled across seasons (spring and autumn) to provide an annually integrated measure of community composition. Invertebrate taxonomy was standardised through the Global Names Resolver (http: / / resolver. globalnames.biodinfo.org/, accessed on 1 September 2020) using the Global Biodiversity Information Facility dataset. Following the approach of [22] we selected six invertebrate biological traits that we expected to respond to these changes (Supplementary Materials, Table S1) and allocated taxa to one modality for each trait using tables in $[22,35]$.

Sample-size based diversity curves were constructed for both hyporheic and benthic invertebrate data using the iNext package in $\mathrm{R}$ [36]. Since species diversity in a sample is highly dependent on sample size or sampling efforts, this approach, which models the cumulative number of taxa found with increasing number of individuals in a sample, provides a robust way of comparing diversity where sample sizes differ. Thus, it allows a fair comparison and assessment of diversities across multiple assemblages (i.e., between control and restored samples; Table 1) that may vary in the size of their species pools or in the way in which they are sampled. Diversity estimates that are independent of sample size effects can be achieved through rarefaction (i.e., 'down-sample' the samples containing the largest number of observed individuals until they contain the same number as the smallest sample) and extrapolation (extrapolate diversity curve to larger sample size, guided by an estimated asymptotic diversity) approaches [31]. Here we fit sample-size based rarefaction and extrapolation curves of Hill numbers (measures of diversity [37]), which provides a unified framework for estimating species diversity, and for making statistical comparisons based upon these estimates [37]. Hill numbers are represented by a diversity order q, which determines the measures' sensitivity to species relative abundances and here we use two of the most widely used species diversity measures: species richness $(q=0)$ and Shannon diversity $(q=1)$, the effective number of common taxa.

For each compartment, sample-size based diversity curves were constructed for each reach (control and impact) and period: before (2013) and after restoration (2, 3 and 5 years post restoration). The $95 \%$ confidence intervals around these fitted curves were calculated based on a bootstrap method [37]. For any fixed sample size in the comparison range, if the $95 \%$ confidence intervals do not overlap, then significant differences at a level of $5 \%$ among the expected diversities (whether interpolated or extrapolated) are guaranteed [36]. As recommended, we extrapolated these curves up to double the smallest sample size or the largest observed sample size between treatments (i.e., the control and impact reaches), whichever is larger [36,37]). Consequently, we selected the largest observed sample size (across all years and reaches) as a base sample size for both the hyporheos and benthos data (2906 and 8419 individuals, respectively) (Table 1). Whilst the curves were extrapolated to these values for the purpose of visualizing the data, we compared the estimates of diversity (richness and Shannon) and their confidence intervals between the control and impact reaches for each sampling year at two points along the sample size continuum: smallest observed sample size (i.e., traditional rarefaction approach) and largest observed sample size (extrapolation approach). Estimates at these points (Table 1) were made using the estimatedD function implemented in the iNEXT package. 
Table 1. Summary statistics for sample-size based rarefaction and extrapolation diversity curves and beta-diversity dissimilarity (CNESSa) analysis.

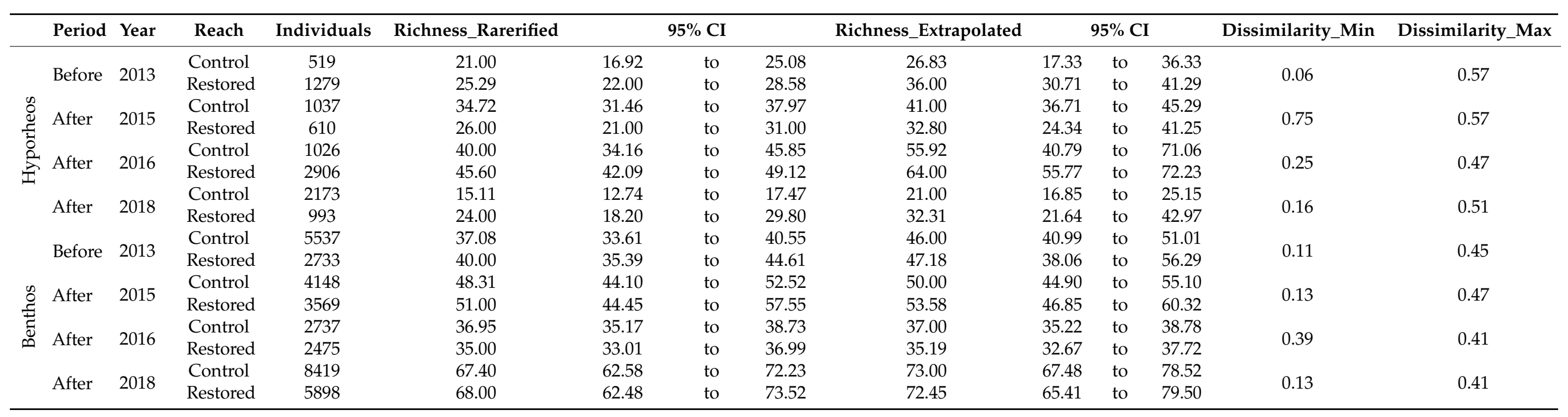


We used the chord-normalised expected species shared index of dissimilarity (CNESS) to provide a measure of $\beta$-diversity between reaches and compartments (hyporheos and benthos). This metric is not confounded by the number of individuals encountered [38,39]) and reflects the probability of obtaining the same set of species when randomly drawing a specific number of individuals, $m$, from a community. High CNESS dissimilarity values in this context reflect a low probability that two samples are drawn from the same community. For low values of $m$ (the sample size parameter) the similarity between samples is strongly determined by dominant species, whereas for high values, the composition of the entire species assemblage becomes increasingly important [33]. CNESSa values were obtained using the R function from Zou and Axmacher [39], which is a standardized version of CNESS dissimilarity where values range between 0 (samples are the same) and 1 (samples are $100 \%$ different). We used $m$ values of 1 and the largest common sample size in each dataset (519 in hyporheos and 2475 in benthos; Table 1) to investigate the dissimilarity of dominant taxa, as well as entire assemblage, in this respect.

\section{Results}

In total, 103 invertebrate taxa were identified from all benthic samples, $68 \%$ of which were identified to species, $22 \%$ to genus level, $8 \%$ to family level and $2 \%$ to order level. The sampling of the hyporheos yielded a total of 71 taxa, $43 \%$ of which were identified to species, $23 \%$ to genus level, $22 \%$ to family level and $12 \%$ to order level.

\subsection{Hyporheos}

Taxon richness prior to restoration was initially higher in the impact reach than the control reach, although $95 \%$ confidence intervals overlap with estimates from the control reach at all sample sizes (interpolated and extrapolated) (Figure 4). However, two years post restoration (2015), taxon richness was significantly lower in the impact compared to the control reach (95\% confidence intervals do not overlap) for both rarefied and extrapolated sample sizes (i.e., smallest (610 individuals) and largest (1037 individuals), observed samples sizes, respectively) (Figure 4). Three years post restoration (2016 sampling), richness curves for the control and impact reach overlapped between both rarefied and extrapolated sample sizes (Figure 4, Table 1), whilst 5 years post restoration (in 2018) taxon richness was significantly higher in the impact compared to the control reach (95\% confidence intervals do not overlap) for rarefied, but not extrapolated, sample sizes (993 and 2173 individuals, respectively).

Unlike richness, Shannon diversity levelled off quickly with increasing sample size, as this index is increasingly dominated by the frequencies of the more common taxa (Figure 4). Prior to restoration, the effective number of common taxa (Shannon Hill number) was identical between the control and impact reach. In the initial period post restoration (2015 sampling), the effective number of common taxa was higher in control versus impact reach, whilst in the latter period post restoration (2016 and 2018) this pattern reversed with more common taxa present in the impact reach (Figure 4). The analysis of beta-diversity supports these findings as dissimilarity in the composition of control and impact assemblages (CNESSa index) was much higher at the first sampling time point post restoration than at any other time point (Table 1$)$, when a low $(m=1)$ but not high $(m=519)$ sample size parameter was used. That is, dissimilarity between reaches was strongly determined by dominant rather than rare taxa. 


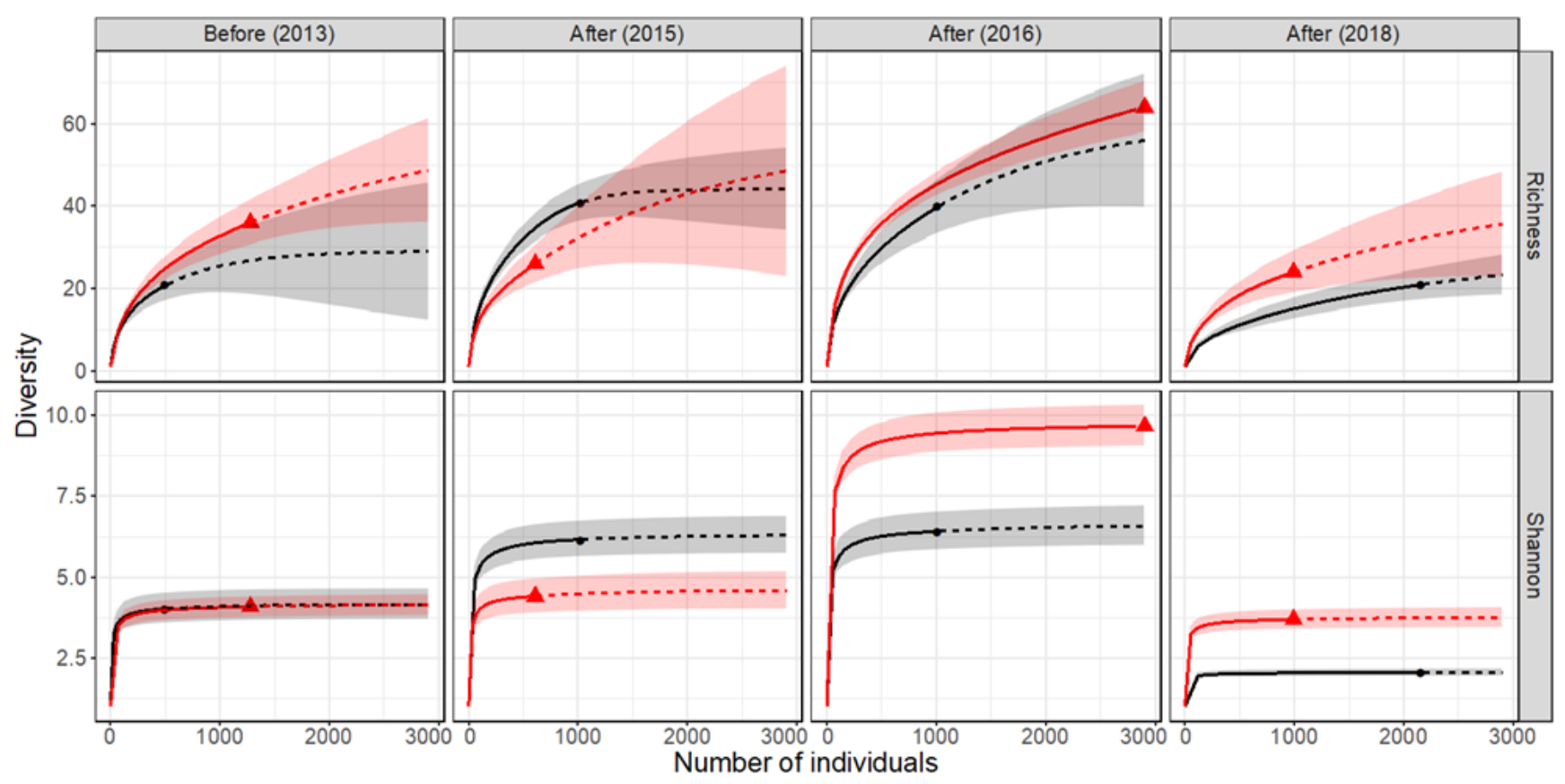

Figure 4. Sample-size based rarefaction (solid line segment) and extrapolation (dotted line segments) diversity curves for hyporheic assemblages in control (black) and impact (red) reaches of the River Lambourn pre and post restoration. The shaded areas represent $95 \%$ confidence intervals.

Differences in hyporheic invertebrate composition at the first sampling time point post restoration (2015) were associated with a change in the frequency of invertebrate traits, with a decrease in the relative abundance of burrowing organisms (Supplementary Materials, Figure S1) that respire through gills (Supplementary Materials, Figure S2). Insecta and Malacostraca were the dominant invertebrate classes (Supplementary Materials, Figure S3). Prior to restoration, the benthos was dominated by Trichoptera (primarily Agapetus sp) followed by Amphipoda (Gammurus pulex/fossarum) with similar proportions recorded at both the control and impact sites (Figure $5 \mathrm{c}$ ). Within the orders, the changes in invertebrate composition at the first sampling time point post restoration were predominantly driven by a relative increase in amphipods (chiefly Gammurus pulex/fossarum) and a decrease in Trichoptera in the control reach (Figure 5a). Supplementary Materials, Table S3 lists the taxa present at each site, year and compartment.

\subsection{Benthos}

Except for small sample sizes, all of the confidence intervals for the two diversity curves for each time point overlap (Figure 6, Table 1), suggesting that taxon richness did not differ statistically between reaches for any of the sampling occasions. Beta-diversity was also similar between the control and impact reach for all time points (Table 1) with little variation in CNESSa dissimilarity values for both low and high values of $m$, signifying limited difference in the composition of dominant and rare species attributed to the effects of restoration. The composition of major invertebrate classes (Supplementary Materials, Figure S3b) was largely conserved across reaches and time points. The relative proportion of the orders showed slight differences prior to restoration and variability throughout the post restoration surveys (Figure $5 b$ ). 

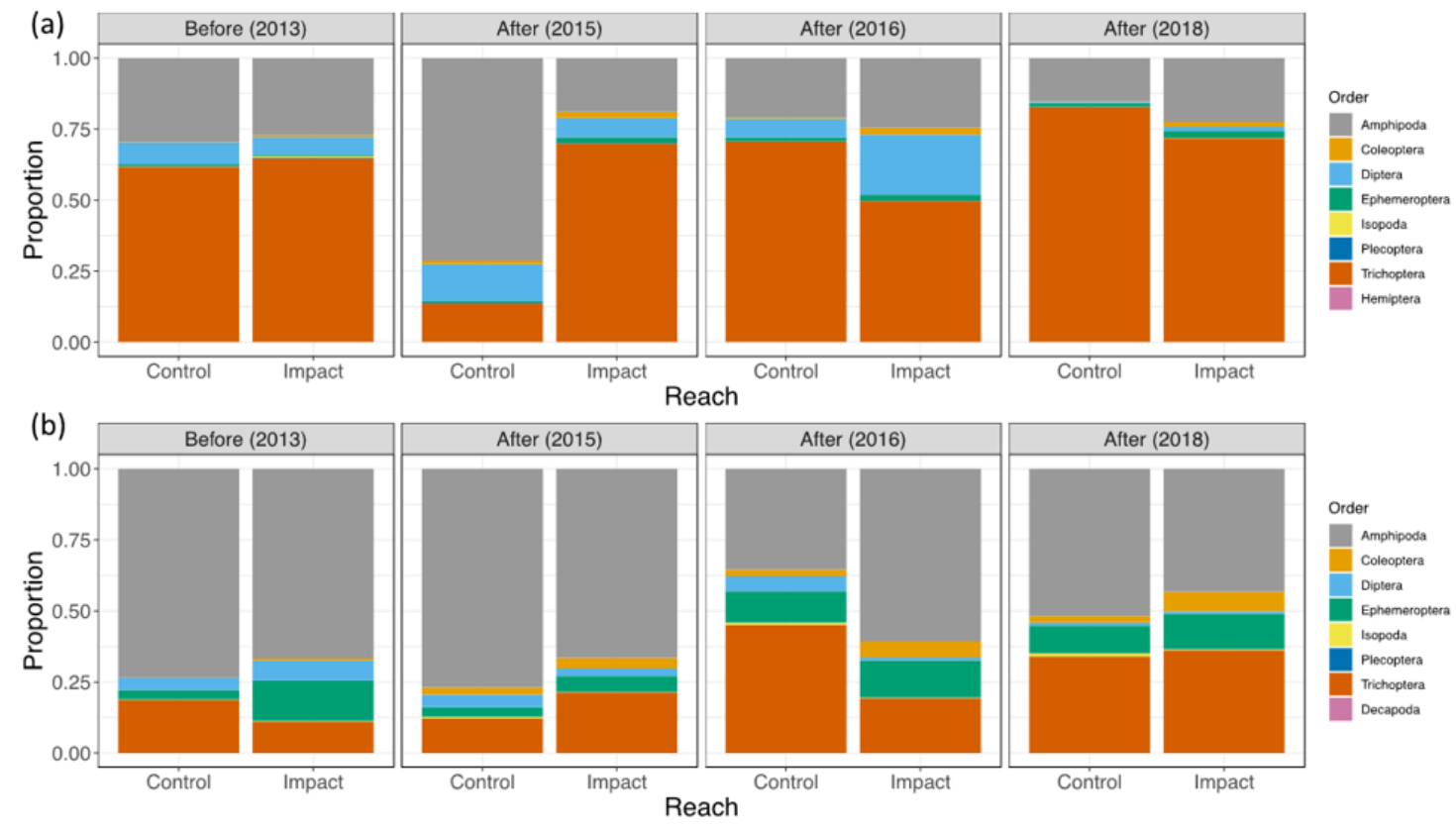

\begin{tabular}{ccccccccc} 
(c) & \multicolumn{9}{c}{ After (2015) } & \multicolumn{2}{c}{ After (2016) } & \multicolumn{2}{c}{ After (2018) } \\
\cline { 2 - 9 } & \multicolumn{2}{c}{ Before (2013) } & \multicolumn{2}{c}{} & & & \\
\cline { 2 - 9 } & HZ vs BZ & HZ v BZ & HZ vs BZ & HZ v BZ & HZ vs BZ & HZ vs BZ & HZ vs BZ & HZ vs BZ \\
Control & Impact & Control & Impact & Control & Impact & Control & Impact \\
\hline$D_{\min }$ & 0.62 & 0.71 & 0.17 & 0.70 & 0.39 & 0.62 & 0.60 & 0.75 \\
$D_{\max }$ & 0.81 & 0.78 & 0.76 & 0.68 & 0.76 & 0.74 & 0.46 & 0.76 \\
\hline
\end{tabular}

Figure 5. Relative abundance of hyporheic (a) and benthic (b) invertebrate orders in the control and impact (restored) reach pre and post restoration. To aid visualization of the data, only the two dominant classes, Insecta and Malacostraca, are shown. Beta-diversity (CNESSa dissimilarity) values between compartments (c) for minimum $\left(\mathrm{D}_{\text {min }}\right)$ and maximum samples sizes $D_{\max }$ ); values can range between 0 (samples are the same) and 1 (samples are $100 \%$ different).
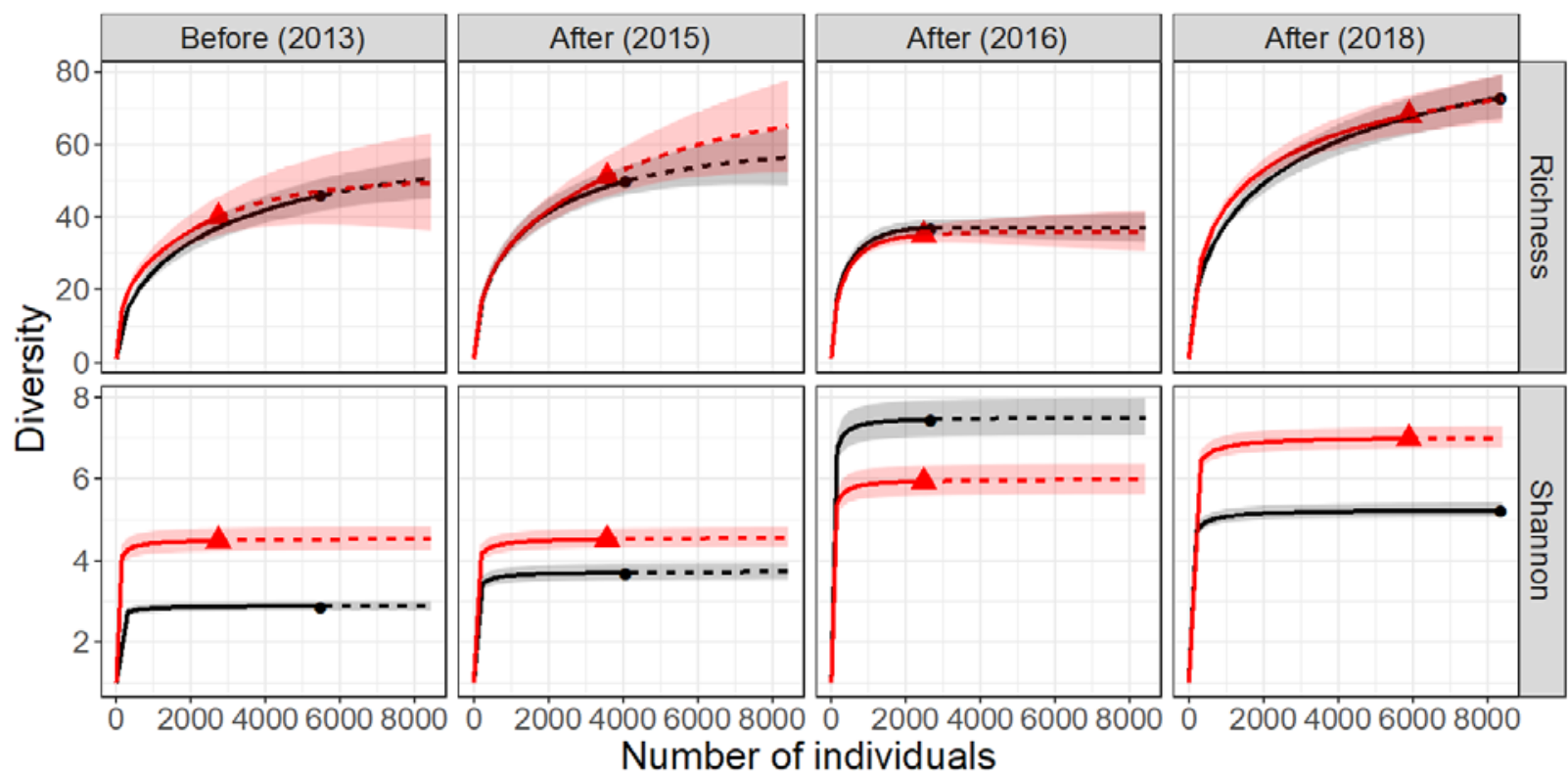

Figure 6. Sample-size based rarefaction (solid line segment) and extrapolation (dotted line segments) diversity curves for benthic assemblages in the control (black) and impact (red) reach of the River Lambourn pre and post restoration. The shaded areas represent $95 \%$ confidence intervals. 


\subsection{Coupling of Hyporheic and Benthic Assemblages}

The analysis of beta-diversity found that dissimilarity between compartments was lowest (i.e., coupling of benthos and hyporheos was greatest) between control assemblages at the first sampling time point post restoration (Figure $5 c$ ), when using a low sample size parameter $(m=1)$. Dissimilarity in composition was much higher when a large $(m=519)$ sample size parameter was used (Figure $5 c)$, i.e., similarity between compartments in the control reach at the first sampling time point post restoration was strongly determined by similarity in numerically dominant taxa, rather than rare invertebrate taxa. Inspection of the dominant taxa in both compartments (from classes Insecta and Malacostraca; Supplementary Materials, Figure S3) revealed that the proportional abundance of amphipods (chiefly Gammurus pulex/fossarum) was the dominant driver of similarity between benthic and hyporheic control reaches at the first sampling time point post restoration (Figure 5). Dissimilarity between hyporheic and benthic assemblages in the impact reach through time was less variable (Figure 5). However, dissimilarity was reduced at the first sampling time point post restoration for the large $(m=519)$ sample size parameter (Figure 5), highlighting a change predominately among rare invertebrate taxa (Supplementary Materials, Table S3).

\section{Discussion}

Our study, for the first time, examined the responses of both hyporheic and benthic riverine communities to a restoration intervention at multiple time points over a 5-year period. Our findings show that alpha diversity (taxon richness and Shannon) in the hyporheos declined in the impact (restored) reach relative to the control reach at the first sampling time point post restoration, and that dissimilarity in community composition in the impact and control reach was highest at this time point. The purpose of notching the weir was to reduce the effects of the impoundment by increasing the velocity of the stream, facilitating the flushing out of accumulated fine sediments in the impact reach, enlarging interstitial pore space and boosting hydrological exchange, and as a result connectivity, between the hyporheic zone and the rest of the river system [40]. This flushing, combined in the short term with the unusually high discharge observed in 2014, may have also washed out species that are adapted to this habitat, resulting in the observed lower diversity. This interpretation is supported by our finding that burrowing organisms with gills (including Tanypodinae, Chironomini, Ceratopogonidae, Simulidae, Rhyacophila and Ephemera) were less frequent in the hyporheos of the impact reach, at this time point (2015), than in the control. These burrowers bio-irrigate the sediment, creating macropores that contribute to the creation of preferential flow paths through the hyporheic zone [41,42]. Undoubtedly, the use of functional trait data provides a helpful additional approach to monitoring the effectiveness of restoration activities [43].

Five years after the restoration, there was a clear signal of higher diversity in the hyporheos of the impact reach relative to the control reach, and diversity was higher than pre-restoration. Over time, a more natural sinuous channel was created in the impact reach. This likely resulted in areas with improved surface water/groundwater exchange where downwelling water brings oxygen and food resources into the hyporheic zone resulting in higher invertebrate diversity [44]. This effect could be particularly pronounced in groundwater-fed streams such as the River Lambourn where downwelling is limited and the river channel is very susceptible to colmation, meaning that connectivity between the benthic and hyporheic zones is reduced [45]. Vegetated and exposed gravel bars also developed in the impact reach. These structures induce lateral hyporheic exchange flows, further increasing the heterogeneity of the available habitat [46].

The fluctuations in diversity we observed throughout our study in both the control and impact reaches underline the importance of undertaking long term post restoration monitoring even though this is rarely done. For example, [47] found that fewer than $4 \%$ of the studies they examined, that were designed to assess the success of river restoration interventions, undertook 5 years of post-restoration monitoring. In the control reach, we found 
marked changes in hyporheos composition and coupling of the benthic and hyporheic assemblages in the first time point after restoration (2015) compared to before restoration and later time points following restoration. This likely results from high discharges in 2014 and highlights that riverine environments, and therefore riverine communities, are inherently variable. Thus, the inclusion of a control reach in river restoration monitoring is essential to account for natural variability in the system and to enable restoration practitioners and managers to understand what types of restoration measures will accomplish their goals [48]. However, a large study of restoration projects in the U.S. [49] found that only $11 \%$ of projects included before and after monitoring at the restored site and at a reference site. Similarly, of the 179 projects added in the River Restoration Centre (RRC) UK National River Restoration Inventory in 2017 only 5\% specifically reported any monitoring outcomes [50].

In contrast to the hyporheos, although there were some observed changes in taxa recorded, we did not detect a signal of restoration on benthic assemblage diversity and composition. This may partly reflect that, although the weir had an impounding influence on habitat composition, the effect on invertebrate composition and community structure was limited. The lack of ability to detect a signal of restoration appears to be a common finding, e.g., [3,51,52], and there is increasing recognition that reach-scale restoration interventions can be fragile; beneficial effects may be reduced by disturbance to the system and reach-scale improvements may be short-lived unless they are complemented with catchment-scale interventions such as changes in agricultural practices to reduce fertilizer and fine sediment inputs $[53,54]$. This is particularly true in streams which are groundwater fed at base flow and where flows that flush out fine sediments are rare [45]. Catchmentscale factors, such as upstream ecological quality, missing source populations [55] and anthropogenic flow alterations [56], may also hamper site specific restoration efforts.

We found that the extent of coupling (i.e., beta-diversity) between the benthos and hyporheos varied during the course of the five-year monitoring. In particular, dissimilarity between compartments was reduced in the control reach at the first sampling time point post restoration and this was driven by an increase in the relative abundance of dominant taxa such as the amphipod Gammurus pulex/fossarum. We also observed a more subtle effect whereby dissimilarity between hyporheic and benthic assemblages in the impact reach was reduced at the first sampling time point post restoration, which was attributed to a change among rare invertebrate taxa. However, it should be noted that different mesh sizes were used to sample the benthos $(250 \mu \mathrm{m})$ and hyporheos $(63 \mu \mathrm{m})$. It is therefore possible that differences in beta-diversity between benthic and hyporheic communities may be impacted to some extent by the occurrence of small taxa in the hyporheic samples (e.g., Ostracoda), that were less well represented in the benthic samples (Supplementary Materials, Table S3). Nonetheless, our results highlight the importance of assessing coupling between hyporheic and benthic assemblages for understanding variation in baseline conditions and the wider impacts of river restoration.

The hyporheos and the benthos responded differently to the restoration procedure in our study, emphasizing that results from monitoring benthic communities cannot be relied upon to inform understanding of the impact of restoration on hyporheic communities. No previous studies have reported the impact of river restoration on the benthos and hyporheos simultaneously. However, given the importance of the hyporheic zone in the provision of ecosystem function and services, such as pollution attenuation and the supply of disturbance and predation refuges $[9,11]$, it is clear that the hyporheic zone should be included in future monitoring protocols that aim to assess river restoration success.

Supplementary Materials: The following are available online at https:/ / www.mdpi.com/article/10 $.3390 / w 13070996 /$ s1, Figure S1: Relative abundance of hyporheic invertebrate movement traits in the control and impact (restored) reach pre and post restoration. Modalities: 1: Ability to burrow 2: non-burrowing, Figure S2: Relative abundance of hyporheic invertebrate respiration traits in the control and impact (restored) reach pre and post restoration. Modalities 1. tegument, 2. gills, 3. Other, Figure S3: Relative abundance of hyporheic (a) and benthic (b) invertebrate groups in the control and 
impact (restored) reach pre and post restoration. To aid visualization of the data, invertebrate classes that make up a very low proportion of total abundance (Entognatha and Hydrozoa) were excluded, along with invertebrates not classified to class level (nematodes), Table S1: Physical characteristics for the impact and control sites on the River Lambourn at each sampling time point from 2013 to 2018, Table S2: Biological traits and modalities of aquatic invertebrates used in this study, Table S3: Taxa present at the impact and control sites on the River Lambourn in each year and compartment (benthic and hyporheic).

Author Contributions: Conceptualization, T.J., J.E., A.L.R., D.M.P.; methodology, T.J., J.E., D.M.P., A.L.R.; formal analysis, D.M.P.; investigation, T.J.; writing—original draft preparation, A.L.R., D.M.P., T.J.; writing-review and editing, A.L.R., D.M.P., J.E., T.J.; visualization, D.M.P., T.J. All authors have read and agreed to the published version of the manuscript.

Funding: This research received no external funding.

Institutional Review Board Statement: Ethical review and approval were waived for this study, because only invertebrates were sampled.

Informed Consent Statement: Not applicable.

Data Availability Statement: The data presented in this study are openly available in FigShare at 10.6084/m9.figshare.14170424.

Acknowledgments: Thanks to Environment Agency staff Glen Meadows (sample collection) and Jenna Ashford (artwork) for their help. The comments of two anonymous reviewers improved the manuscript. The views expressed within this paper are those of the authors and not those of the Environment Agency.

Conflicts of Interest: The authors declare no conflict of interest.

\section{References}

1. Wohl, E.; Lane, S.N.; Wilcox, A.C. The science and practice of river restoration. Water Resour. Res. 2015, 51, 5974-5997. [CrossRef]

2. Palmer, M.A.; Ambrose, R.F.; Poff, N.L. Ecological theory and community restoration ecology. Restor. Ecol. 1997, 5, 291-300. [CrossRef]

3. Lorenz, A.W.; Haase, P.; Januschke, K.; Sundermann, A.; Hering, D. Revisiting restored river reaches-Assessing change of aquatic and riparian communities after five years. Sci. Total Environ. 2018, 613-614, 1185-1195. [CrossRef] [PubMed]

4. Beechie, T.J.; Sear, D.A.; Olden, J.D.; Pess, G.R.; Buffington, J.M.; Moir, H.; Roni, P.; Pollock, M.M. Process-based principles for restoring river ecosystems. Bioscience 2010, 60, 209-222. [CrossRef]

5. Palmer, M.A.; Hondula, K.L.; Koch, B.J. Ecological Restoration of Streams and Rivers: Shifting Strategies and Shifting Goals. Annu. Rev. Ecol. Evol. Syst. 2014, 45, 247-269. [CrossRef]

6. Boulton, A.J.; Datry, T.; Kasahara, T.; Mutz, M.; Stanford, J.A. Ecology and management of the hyporheic zone: Streamgroundwater interactions of running waters and their floodplains. J. N. Am. Benthol. Soc. 2010, 29, 26-40. [CrossRef]

7. Stegen, J.C.; Fredrickson, J.K.; Wilkins, M.J.; Konopka, A.E.; Nelson, W.C.; Arntzen, E.V.; Chrisler, W.B.; Chu, R.K.; Danczak, R.E.; Fansler, S.J.; et al. Groundwater-surface water mixing shifts ecological assembly processes and stimulates organic carbon turnover. Nat. Commun. 2016, 7, 11237. [CrossRef]

8. Merill, L.; Tonjes, D.J. A review of the hyporheic zone stream restoration, and means to enhance denitrification. Crit. Rev. Environ. Sci. Technol. 2014, 44, 2337-2379. [CrossRef]

9. Lewandowski, J.; Putschew, A.; Schwesig, D.; Neumann, C.; Radke, M. Fate of organic micropollutants in the hyporheic zone of a eutrophic lowland stream: Results of a preliminary field study. Sci. Total Environ. 2011, 409, 1824-1835. [CrossRef]

10. Liu, Y.; Liu, C.; Nelson, W.C.; Shi, L.; Xu, F.; Liu, Y.; Yan, A.; Zhong, L.; Thompson, C.; Fredrikson, J.K.; et al. Effect of water chemistry and hydrodynamics on nitrogen transformation activity and microbial community functional potential inhyporheic zone sediment columns. Environ. Sci. Technol. 2017, 51, 4877-4886. [CrossRef]

11. Robertson, A.L.; Wood, P.J. Ecology of the hyporheic zone: Origins, current knowledge and future directions. Fundam. Appl. Limnol. 2010, 176, 279-289. [CrossRef]

12. Brunke, M.; Gonser, T. The ecological significance of exchange processes between rivers and groundwater. Freshw. Biol. 1997, 37, 1-33. [CrossRef]

13. Rutherford, J.E.; Hynes, H.B.N. Dissolved organic carbon in streams and groundwater. Hydrobiologia 1987, 154, 33-48. [CrossRef]

14. Boano, F.; Harvey, J.W.; Marion, A.; Packman, A.I.; Revelli, R.; Ridolfi, L.; Wörman, A. Hyporheic flow and transport processes: Mechanisms, models, and biogeochemical implications. Rev. Geophys. 2014, 52, 603-679. [CrossRef]

15. Hancock, P. The Effects of River Stage Fluctuations on the Hyporheic and Parafluvial Ecology of the Hunter River, New South Wales. Ph.D. Thesis, University of New England, Armidale, NSW, Australia, 2004.

16. Arthington, A.H.; Pusey, B.J. Flow restoration and protection in Australian rivers. River Res. Appl. 2003, 19, 377-395. [CrossRef] 
17. Buss, S.; Cai, Z.; Cardenas, B.; Fleckenstein, J.; Hannah, D.; Heppell, K.; Hulme, P.; Ibrahim, T.; Kaeser, D.; Krause, S.; et al. The Hyporheic Handbook: A Handbook on the Groundwater-Surface-Water Interface and Ecology of the Hyporheic Zone for Environmental Managers; 2009 Environment Agency Science Report SC0 50070; Environment Agency: Bristol, UK, 2009.

18. Palmer, M.A.; Bely, A.E.; Berg, K.E. Response of invertebrates to lotic disturbance: A test of the hyporheic refuge hypothesis. Oecologia 1992, 89, 182-194. [CrossRef]

19. Lafont, M.; Vivier, A.; Nogueira, S.; Namour, P.; Breil, P. Surface and hyporheic oligochaete assemblages in a French suburban stream. Hydrobiologia 2006, 564, 183-193. [CrossRef]

20. James, A.B.W.; Dewson, Z.S.; Death, R.G. Do stream macroinvertebrates use instream refugia in response to severe short-term flow reduction in New Zealand streams? Freshwat. Biol. 2008, 53, 1316-1334. [CrossRef]

21. Descloux, S.; Datry, T.; Marmonier, P. Benthic and hyporheic invertebrate assemblages along a gradient of increasing streambed colmation by fine sediment. Aquat. Sci. 2013, 75, 493-507. [CrossRef]

22. Descloux, S.; Datry, T.; Usseglio-Polatera, P. Trait-based structure of invertebrates along a gradient of sediment colmation: Benthos versus hyporheos responses. Sci. Total Environ. 2014, 466, 265-276. [CrossRef]

23. Stubbington, R.; Boulton, A.J.; Little, S.; Wood, P.J. Changes in invertebrate assemblage composition in benthic and hyporheic zones during a severe supraseasonal drought. Freshwat. Sci. 2015, 34, 344-354. [CrossRef]

24. Magliozzi, C.; Usseglio-Polatera, P.; Meyer, A.; Grabowski, R.C. Functional traits of hyporheic and benthic invertebrates reveal importance of wood-driven geomorphological processes in rivers. Funct. Ecol. 2019, 33, 1758-1770. [CrossRef]

25. Peralta-Maraver, I.; Galloway, J.; Posselt, M.; Arnon, S.; Reiss, J.; Lewandowski, J.; Robertson, A. Environmental filtering and community delineation in the streambed ecotone. Sci. Rep. 2019, 8, 15871. [CrossRef]

26. Negishi, J.N.; Terui, A.; Nessa, B.; Miura, K.; Oiso, T.; Sumitomo, K.; Kyuka, T.; Yonemoto, M.; Nakamura, F. High resilience of aquatic community to a 100-year flood in a gravel-bed river. Landsc. Ecol. Eng. 2019, 15, 143-154. [CrossRef]

27. Peralta-Maraver, I.; Reiss, J.; Robertson, A.L. Interplay of hydrology, community ecology and pollution attenuation in the hyporheic zone. Sci. Total Environ. 2018, 610-611, 267-275. [CrossRef]

28. Bou, C.; Rouch, R. Un nouveau champ de recherches sur la faune aquatique souterraine. CR Acad. Sci. 1967, 265, 369-370.

29. Boulton, A.J.; Dole-Olivier, M.-J.; Marmonier, P. Optimizing a sampling strategy for assessing hyporheic invertebrate biodiversity using the Bou-Rouch method: Within site replication and sample volume. Archiv. Hydrobiol. 2003, 156, 431-456. [CrossRef]

30. Kibichii, S.; Baars, J.R.; Kelly-Quinn, M. Optimising sample volume and replicates using the Bou-Rouch method for the rapid assessment of hyporheic fauna. Mar. Freshw. Res. 2009, 60, 83-96. [CrossRef]

31. Pretty, J.L.; Hilldrew, A.G.; Trimmer, M. Nutrient dynamics in relation to surface-groundwater hydrological exchange in a groundwater fed chalk stream. J. Hydrol. 2006, 330, 84-100. [CrossRef]

32. Davy-Bowker, J.-D.; Sweeting, W.; Wright, N.; Clark, R.T.; Arnott, S. The distribution of benthic and hyporheic macroinvertebrates from the heads and tails of riffles. Hydrobiologia 2006, 563, 109-123. [CrossRef]

33. Pacioglu, O.; Robertson, A.L. The invertebrate community of the chalk stream hyporheic zone: Spatio-temporal distribution patterns. Knowl. Manag. Aquat. Ecosyst. 2017, 418, 10. [CrossRef]

34. Murray-Bligh, J.A.D.; Furse, M.T.; Jones, F.H.; Gunn, R.J.M.; Dines, R.A.; Wright, J.F. Procedure for Collecting and Analysing Macroinvertebrate Samples for RIVPACS; Joint publication by the Institute of Freshwater Ecology and the Environment Agency; Institute of Freshwater Ecology and the Environment Agency: Wareham, UK, 1997; p. 162.

35. Tachet, H.; Richoux, P.; Bournaud, M.; Usseglio-Polatera, P. Invertebres d'eau douce. Systematique, biologie, ecologie. CNRS Editions: Paris, France, 2010; p. 607.

36. Hsieh, T.C.; Ma, K.H.; Chao, A. iNEXT: An R package for rarefaction and extrapolation of species diversity (Hill numbers). Methods Ecol. Evol. 2016, 7, 1451-1456. [CrossRef]

37. Chao, A.; Gotelli, N.J.; Hsieh, T.C.; Sander, E.L.; Ma, K.H.; Colwell, R.K.; Ellison, A.M. Rarefaction and extrapolation with Hill numbers: A framework for sampling and estimation in species diversity studies. Ecol. Monogr. 2014, 84, 45-67. [CrossRef]

38. Legendre, P.; Gallagher, E.D. Ecologically meaningful transformations for ordination of species data. Oecologia 2001, 129, 271-280. [CrossRef]

39. Zou, Y.; Axmacher, J.C. The Chord-Normalized Expected Species Shared (CNESS)-distance represents a superior measure of species turnover patterns. Methods Ecol. Evol. 2019, 11, 273-280. [CrossRef]

40. Hancock, P. Human impacts on the stream-groundwater exchange zone. Environ. Manag. 2002, 29, 761-781. [CrossRef]

41. Rillig, M.P.; Ziersch, L.; Hempel, S. Microplastic transport in soil by earthworms. Sci. Rep. 2017, 7, 1362. [CrossRef] [PubMed]

42. Re, V. Shedding light on the invisible: Addressing the potential for groundwater contamination by plastic microfibers. Hydrogeol. J. 2019, 27, 2719-2727. [CrossRef]

43. Tullos, D.; Penrose, D.; Jennings, G.; Cope, W. Analysis of functional traits in reconfigured channels: Implications for the bioassessment and disturbance of river restoration. J. N. Am. Benthol. Soc. 2009, 28, 80-92. [CrossRef]

44. Franken, R.J.M.; Storey, R.G.; Dudley Williams, D. Biological, chemical and physical characteristics of downwelling and upwelling zones in the hyporheic zone of a north-temperate stream. Hydrobiologia 2001, 444, 183-195. [CrossRef]

45. Sear, D.A.; Armitage, P.D.; Dawson, F.H. Groundwater dominated rivers. Hydrol. Process. 1999, 13, 255-276. [CrossRef]

46. Kasahara, T.; Hill, A.R. Instream restoration: Its effectson lateral stream-subsurface water exchange in urban and agricultural streams in Southern Ontario. River Res. Appl. 2007, 23, 801-814. [CrossRef] 
47. Rubin, Z.; Kondolf, G.M.; Rios-Touma, B. Evaluating Stream Restoration Projects: What Do We Learn from Monitoring? Water 2017, 9, 174. [CrossRef]

48. Bernhardt, E.S.; Palmer, M.; Allan, J.D.; Alexander, G.; Barnas, K.; Brooks, S.; Carr, J.; Clayton, S.; Dahm, C.; Follstad-Shah, J.; et al. Synthesizing US river restoration efforts. Science 2005, 308, 636-637. [CrossRef] [PubMed]

49. Bernhardt, E.S.; Sudduth, E.B.; Palmer, M.A.; Allan, J.D.; Meyer, J.L.; Alexander, G.; Follastad-Shah, J.; Hassett, B.; Jenkinson, R.; Lave, R.; et al. Restoring rivers one reach at a time: Results from a survey of US river restoration practitioners. Restor. Ecol. 2007, 15, 482-493. [CrossRef]

50. England, J.; Naura, M.; Mant, J.; Skinner, K. Seeking river restoration appraisal best practice: Supporting wider national and international environmental goals. Water Environ. J. 2019, 34, 1003-1011. [CrossRef]

51. Louhi, P.; Mykrä, H.; Paavola, R.; Huusko, A.; Vehanen, T.; Mäki-Petäys, A.; Muotka, T. Twenty years of stream restoration in Finland: Little response by benthic macroinvertebrate communities. Ecol. Appl. 2011, 21, 1950-1961. [CrossRef]

52. Haase, P.; Hering, D.; Jahnig, S.C.; Lorenz, A.W.; Sundermann, A. The impact of hydromorphological restoration on river ecological status: A comparison of fish, benthic invertebrates and macrophytes. Hydrobiologica 2013, 704, 475-488. [CrossRef]

53. Sarriquet, P.E.; Bordenave, P.; Marmonier, P. Effects of bottom sediment restoration on interstitial habitat characteristics and benthic macroinvertebrate assemblages in a headwater stream. River Res. Appl. 2007, 23, 815-828. [CrossRef]

54. Knott, J.; Mueller, M.; Pander, J.; Geist, J. Effectiveness of catchment erosion protection measures and scale-dependent response of stream biota. Hydrobiologia 2019, 830, 77-92. [CrossRef]

55. Tonkin, J.D.; Stoll, S.; Sundermann, A.; Haase, P. Dispersal distance and the pool of taxa, but not barriers, determine the colonisation of restored river reaches by benthic invertebrates. Freshwat. Biol. 2014, 59, 1843-1855. [CrossRef]

56. Palmer, M.; Ruhi, A. Linkages between flow regime, biota, and ecosystem processes: Implications for river restoration. Science 2019, 365, eaaw2087. [CrossRef] [PubMed] 